\title{
Removing Disperse red 60 and Reactive blue 19 dyes removal by using Alcea rosea root mucilage as a natural coagulant
}

\author{
Tahereh Zarei Mahmoudabadi ${ }^{1}$, Parvaneh Talebi ${ }^{1}$ and Mahrokh Jalili ${ }^{2 *}$
}

\begin{abstract}
In terms of health, dyes have carcinogenic, mutagenic and toxic properties and can have adverse effects on health and the environment. Therefore, sewage containing to dyes must be purified before being discharged into the environment. The current study aimed to investigate the effectiveness of Alcea rosea root extract in Disperse red 60 and Reactive blue 19 dyes removal from synthetic sewage. In this study, the effect of different indices including pH (5-11), Alcea rosea concentration (50-300 mg/L) and initial dye concentration (10-80 mg/L) was investigated. During the tests, the coagulant was stirred with rapid mixing at a speed of $250 \mathrm{rpm}$ for $2 \mathrm{~min}$. In the following, the speed (30$60 \mathrm{rpm}$ ) and the time (10-25 min) were used for slow mixing and after mixing the effect of settling time (10-60 min) and temperature (20-70) on removal efficiency of Disperse and Reactive dyes was investigated. The results showed that the maximum of removal efficiency of Disperse and Reactive dyes in optimum conditions including $(\mathrm{pH}=11$, coagulant concentration $=200$ and $250 \mathrm{mg} / \mathrm{L}$, dye concentration 40 and $20 \mathrm{mg} / \mathrm{L}$, speed $60 \mathrm{rpm}$, during 15 min with settling time 60 min and temperature $60{ }^{\circ} \mathrm{C}$ obtained $86 \%$ and $68 \%$, respectively. According to the result, the Alcea rosea coagulant has the best ability in removing dyes from aqueous solutions and sewage, especially Disperse dyes. Disperse dye is much eliminated in the coagulation process due to its lower solubility, higher suspending materials and less required solved chemical oxygen demand to the total chemical oxygen demand (SCOD/TCOD).
\end{abstract}

Keywords: Dye removal, Sewage treatment, Natural coagulant, Alcea rosea

\section{Introduction}

In recent years, development of industries has been caused environmental pollution because there are organic and inorganic pollutants, heavy metals, dyes, etc. in their sewage from production process (Santhi et al. 2016). Due to the complicated and non-biodegradable molecular structure, dye is the most important pollutants in the industries, that can't be removed by biological methods (Cengiz et al. 2012). But the chemical purification procedure can be useful in the removal of this contaminant (Chen et al. 2018). Annual production of dyes is estimated at more than 700,000 tones (Moussavi and Mahmoudi 2009). The presence of organic dyestuffs in

\footnotetext{
*Correspondence: Mahro.jalili@gmail.com

${ }^{2}$ Department of Environmental Health Engineering, Shahid Sadoughi University of Medical Science, Abarkouh Paramedical School, Yazd, Iran Full list of author information is available at the end of the article
}

the wastewater prevents the penetration of light into the receiving waters, disrupting in the photosynthesis of living aquatic organisms in these resources, and reducing the transfer of oxygen into the water. Also increasing the toxic effects of the accumulation of pollutants causes irreparable damage to the environment (Haque et al. 2015; Yu et al. 2009) and dangerous to public health due to adverse health and environmental impacts (Tie et al. 2015). Discharging these wastewaters into rivers and lakes without any treatment makes a reduction in the quality of surface and underground water resources (Raman and Kanmani 2016).

Three dyes that commonly used in industries, and based on their chemical nature are classified as follows: acidic, Reactive and Disperse Dyes. Acidic dyes are water-soluble and Anionic compounds that used for nylon, wool, and silk fibers (Phalakornkule et al. 2010). Disperse dyes are part of the derivatives of nitro-phenyl 

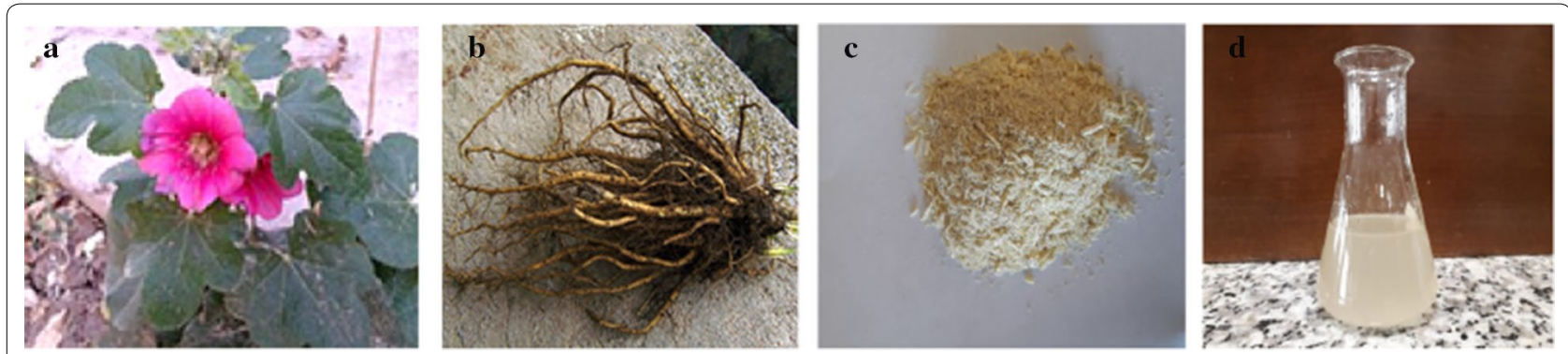

Fig. 1 Used species (a), root (b), powder (c), mucilage (d) of Alcea rosea in this study

amine and azoanthraquinone dyes and don't contain sulfated groups. Disperse dyes are soluble in yarn but insoluble in water (El-sayed et al. 2012). Reactive dyes are anionic, soluble in water and very stable. Due to circular aromatic structure, have carcinogenic and mutagenic in term of health and can make allergies and skin problems (Al-Momani et al. 2002). In recent years, the idea of economic savings has become a necessity, so designing some methods for removing contaminants should be based on using materials that can remove these pollutants at the lowest cost. Recently, the methods of using natural materials like plant extracts as coagulants that are biodegradable and low cost have provided favorable result in the direction of wastewater treatment in combination with other materials (Kasprzyk and Gajewska 2018). One of these methods for wastewater treatment is coagulation and flocculation, which is widely used in the initial treatment of sewage (Zarei Mahmudabadi et al. 2018). There are various processes for removing of dyes from industrial wastewater that can point to processes such as biological process, chemical Oxidation, Adsorption, Photo catalyst, Electrocoagulation, Coagulation, and Flocculation (Yagub et al. 2014; Zodi et al. 2013; Guimarães et al. 2012; Gupta et al. 2012; Verma and Dash 2012; Wang et al. 2009). In the meantime, using natural coagulants is more widely accepted because of its biodegradability, low cost, and lack of residual material in the wastewater (Maurya and Daverey 2018).

Natural coagulants that is used in other studies include the chitosan, moringa seeds, banana skin powder, scrotum powder, banana stalk hair, papaya seed powder, etc. (Vilaseca et al. 2014; Veeramalini et al. 2012). One of these natural coagulants is Alcea rosea root extract that their effectiveness on Disperse and Reactive dyes removal hasn't been investigated, yet.

Alcea rosea, the common hollyhock, is an ornamental plant in the Malvaceae. In herbal medicine, it is believed the Hollyhock is an emollient and laxative. It is used to control inflammation, to stop bedwetting and as a mouthwash in cases of bleeding gums. The flowers are a range of dyes from white to dark red, including pink, yellow and orange. Different dyes prefer different soils. It was imported into Europe from southwest of China during, or possibly before, 15th century. The flowers and leaves have about 6 to 9 percent of mucilage that the highest percentage of which is slightly before flowering. Also, flavonoids and a very small amount of essential oils are from other flowers and leaves. The most important Alcea root composition is its mucilage, which varies in different seasons and reaches the maximum in winter. Different sources mention the percentage of root Mucilage between 10 and 35\%. Mucilage induces rhamnose, galactose, and galacturonic acid through hydrolysis (Ahmadi et al. 2014; Shah et al. 2011).

So far, multiple studies have been done on removing Disperse and Reactive dyes using natural coagulants, which are coated by Ocimum basilicum for textile wastewater treatment (Shamsnejati et al. 2015), natural zeolite modified with phosphoric acid and sulfuric acid (Maleki et al. 2013), Plantago major extract as a natural coagulant in removal of Reactive blue 19 dye (Zarei Mahmoudabadi et al. 2019) and natural coagulant in removing other dyes including reactive yellow 2 dye (Veeramalini et al. 2012), effective performance of chitosan, Surjana seed powder and corn seed powder as a natural coagulant in removing Congo red dye from aqueous solutions (Patel and Vashi 2012) and they have had a good performance.

However, due to advantages such as ease of use, naturalness, availability, and possibility of producing secondary compounds less than chemical methods, using Alcea root mucilage can be used as a coagulant in the removal of sewage containing dyes. This study aimed to investigate the removal of Disperse red 60 and Reactive blue 19 dyes from synthetic sewage by coagulation process and by using Alcea rosea root mucilage as a natural coagulant.

\section{Materials and methods}

Preparation of Alcea rosea mucilage extract

Alceahas 60 species, which Alcea rosea was used in the current study (With pink flowers) (see Fig. 1). To prepare, 
Table 1 Basic properties of the investigated dyes (Siddique et al. 2011; El-sayed et al. 2012)

\begin{tabular}{lll}
\hline Characteristic & Dispersion red 60 & Reactive blue 19 dyes \\
\hline Chemical formula & $\mathrm{C}_{20} \mathrm{H}_{13} \mathrm{NO}_{4}$ & $\mathrm{C}_{22} \mathrm{H}_{16} \mathrm{~N}_{2} \mathrm{Na}_{2} \mathrm{O}_{11} \mathrm{~S}_{3}$ \\
Molecular weight & $331.32 \mathrm{~g} / \mathrm{mol}$ & $626.55 \mathrm{~g} / \mathrm{mol}^{2}$ \\
$\mathrm{CAS}$ & $17418-85-5$ & $2580-78-1$ \\
$\mathrm{C} . \mathrm{l}$ & 60,756
\end{tabular}

the root were naturally dried and then milled. Then, $2.5 \mathrm{~g}$ of dried root powder was added to $100 \mathrm{~mL}$ of $0.5 \mathrm{M}$ sodium chloride which was prepared with distilled water, and the resulting solution was shaken for $1 \mathrm{~h}$ by using a magnetic magnet (Subramonian et al. 2014). In this study, a specific mesh for coagulant powder was not used. $1 \mathrm{~g}$ of coagulant root after milling was used directly for mucilage extraction.

The resulting milky solution mucilage was passed through a fabric filter and used. This action was carried out to extract and activate the coagulation components. $25 \mathrm{~g} / \mathrm{L}$ of storage milky solution of Alcea rosea root mucilage is prepared on a daily basis. This solution was investigated as a coagulant in this study.

\section{Measurement of dye removal}

In this study the physical and chemical properties of the used dyes are shown in Table 1.

Measurement of dyes removal was performed by using absorption measurement. In this way at first, a solution of dye at a concentration of $1000 \mathrm{mg} / \mathrm{L}$ was prepared. Standard solutions were prepared at concentrations of 5, 10, 20, 40, 60, 80 and $90 \mathrm{mg} / \mathrm{L}$. With the DR6000 spectrophotometer, $(\mathrm{HACH})$, the adsorption rate for Disperse red 60 and Reactive blue 19 at wavelength of $586 \mathrm{~nm}$ and $592 \mathrm{~nm}$ obtained, respectively. Calibration curve was drawn. The initial dye concentration was determined by using a calibration curve. The percentage of dye removal was calculated by using the below equation:

$$
\text { Dye removal }(\%)=\frac{\left(\mathrm{Abs}_{0}-\mathrm{Abs}\right)}{\mathrm{Abs}_{0}} \times 100
$$

$\mathrm{Abs}_{0}$ is the dye absorption mean before treatment and Abs is the dye concentration after the treatment process.

This empirical study was conducted on a laboratory scale in the water and wastewater chemistry laboratory of the Faculty of Health of Yazd University of Medical Sciences.

After coagulant preparation, $100 \mathrm{mg} / \mathrm{L}$ was added to $1000 \mathrm{~mL}$ of dyeing solution at a concentration of $40 \mathrm{mg} / \mathrm{L}$ with different $\mathrm{pH}(5-10)$. $\mathrm{PH}$ adjustment was performed by using sodium hydroxide and one chloride acid (manufactured by Merck $\mathrm{GmbH}$ ) and a $\mathrm{pH}$ meter (HAC multiparameter manufactured by the HQ40 model). After mixing with Jarrett (manufactured by HACH USA, model 402-7790), the settling time about $60 \mathrm{~min}$ were given to the solution, and then samples were collected from $3 \mathrm{~cm}$ below the sewage surface using pipettes. By measuring the removal efficiency of the sample, the optimum $\mathrm{pH}$ for coagulant was determined. Subsequently, considering the optimal $\mathrm{pH}$ and constant dye concentration, different doses of Alcea rosea (50, 100, 150, 200, 250 and $300 \mathrm{mg} / \mathrm{L}$ ) were added to the sample. By measuring the removal efficiency of the paint, the optimal dose of Alcea rosea was determined for both disperse and reactive dyes. In the next step, with the optimal conditions obtained from the previous steps, the effects of different concentrations of dye $(10,20,40,60$ and $80 \mathrm{mg})$ were investigated. During the tests, the coagulant was stirred at a speed of $250 \mathrm{rpm}$ for $2 \mathrm{~min}$. These values were kept constant for all experiments. Then, various speeds (30, 40 and $50 \mathrm{rpm}$ ) were investigated for 10, 15, 20 and $25 \mathrm{~min}$ to slow mixing. Finally, having optimum conditions that obtained from the previous steps, the effect of different sedimentation times (10, 20, 30, 40, 50 and $60 \mathrm{~min})$ were investigated after finishing the mixing process.

It should be noted that at all steps of the experiments were carried out at $40{ }^{\circ} \mathrm{C}$. Finally, the effects of different temperatures $\left(20,30,40,50,60\right.$ and $\left.70{ }^{\circ} \mathrm{C}\right)$ were investigated for optimal temperature determination. 


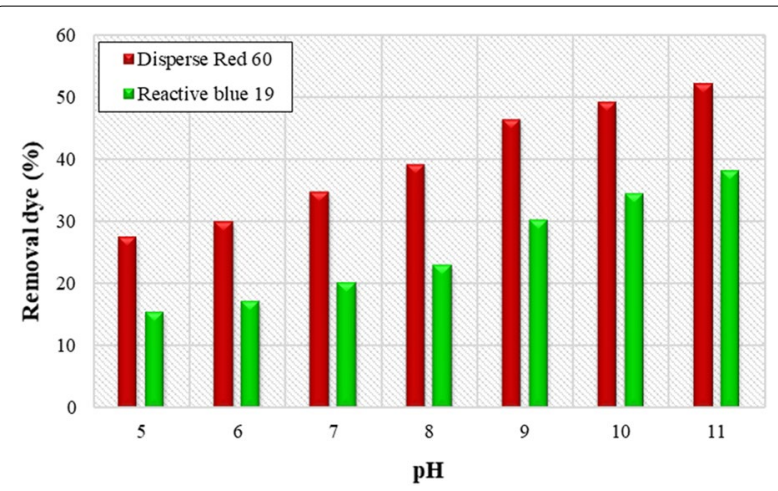

Fig. 2 The effect of initial pH on the efficiency of removal of Disperse red 60 and Reactive blue 19 dyes. (A/cea rosea $=100 \mathrm{mg} / \mathrm{L}$; initial dye concentration $=40 \mathrm{mg} / \mathrm{L}$ )

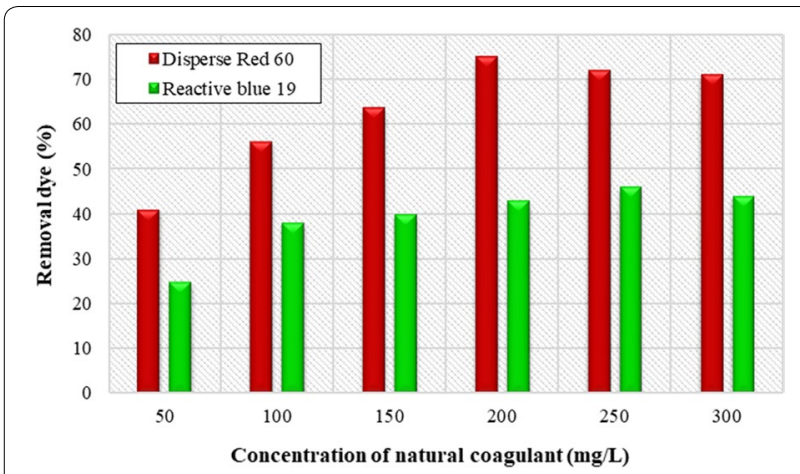

Fig. 3 Effect of Alcea rosea concentration on removal efficiency of Disperse red 60 and Reactive blue 19 dyes. (Initial pH=11 and initial dye concentration $=40 \mathrm{mg} / \mathrm{L}$ )

\section{Results}

\section{PH effects}

$\mathrm{PH}$ of the sample plays an important role in the process of coagulation and flocculation, so that each coagulant in a particular $\mathrm{pH}$ can have a significant effect. Figure 2 shows the effect of Alcea rosea coagulant in dye removal in different $\mathrm{pH}$. The results indicate that $\mathrm{pH}=11$ is the most appropriate $\mathrm{pH}$. So that removal efficiency for Alcea rosea coagulant at $\mathrm{pH}=11$ was $55.3 \%$ and $43.4 \%$ respectively for Reactive and Dispersive dyes. Then all experiments were performed at optimal $\mathrm{pH}$.

\section{The effect of coagulant dose}

The optimal concentration of Alcea rosea coagulant, as a natural coagulant, was determined for Disperse and Reactive dyes removal at optimal $\mathrm{pH}$ for each sample (Fig. 3). As it can be seen, with increasing in the amount of natural coagulant, the amount of dye removal increased. The maximum removal of Disperse

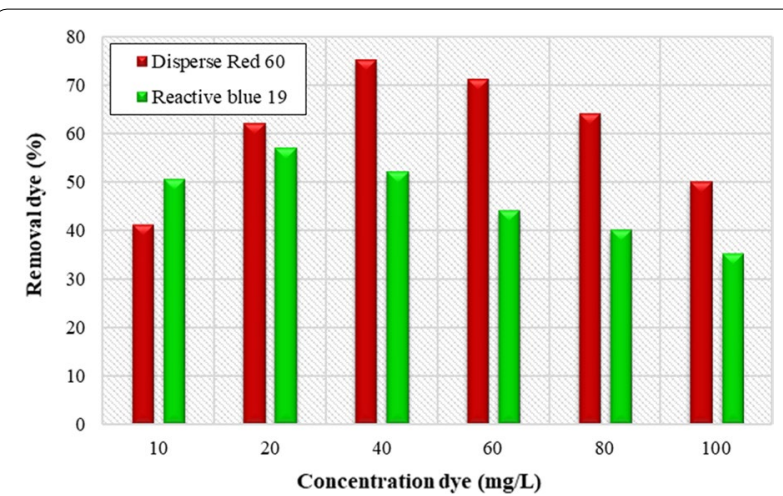

Fig. 4 Effect of initial dye concentrations on removal efficiency of Disperse red 60 and Reactive blue 19 dyes. (Initial pH =11 and Alcea rosea concentration $=200 \mathrm{mg} / \mathrm{L}$ for Disperse experiments; initial $\mathrm{pH}=11$ and concentration $=250 \mathrm{mg} / \mathrm{L}$ for Reactive experiments)

and Reactive dyes were $75 \%$ at $200 \mathrm{mg} / \mathrm{L}$ and $46 \%$ at $250 \mathrm{mg} / \mathrm{L}$ of Alcea rosea root mucilage, respectively.

\section{The effect of initial dye concentration}

Figure 4 shows removal efficiency of dye in different concentrations of the dye under obtained optimal conditions from the previous steps $(\mathrm{pH}$ and coagulant concentration). The results showed that the highest removal of Disperse dye with $75 \%$ efficiency was obtained at $40 \mathrm{mg} / \mathrm{L}$ of dye concentration. The maximum Reactive dye removal efficiency was also achieved with $56.8 \%$ efficiency at a concentration of $20 \mathrm{mg} / \mathrm{L}$. In the following experiments, concentration of $40 \mathrm{mg} / \mathrm{L}$ and $20 \mathrm{mg} / \mathrm{L}$ of Dispersion and Reactive dyes were used, respectively.

\section{The effect of slow mixing speed}

The results of the effect of slow mixing speed(30 to $60 \mathrm{rpm}$ ) on the dye removal efficiency have shown in Fig. 5. The results show that with increasing the slow mixing speed, the dye removal efficiency increases too. So that, the maximum removal efficiency was $78.2 \%$ and $59.4 \%$ for Dispersed and Reactive dyes at a mixing rate of $60 \mathrm{rpm}$, respectively. As a result, the mixing speed of $60 \mathrm{rpm}$ was chosen as the optimal mixing speed.

\section{The effect of slow mixing time}

Figure 6 shows the effect of slow mixing time (10$25 \mathrm{~min}$ ) on the amount of dye removal. As can be seen, the highest removal efficiency of Disperse and Reactive dyes was obtained in a $15 \min (81 \%$ and $62 \%$, respectively). As the mixing time increases, no significant 


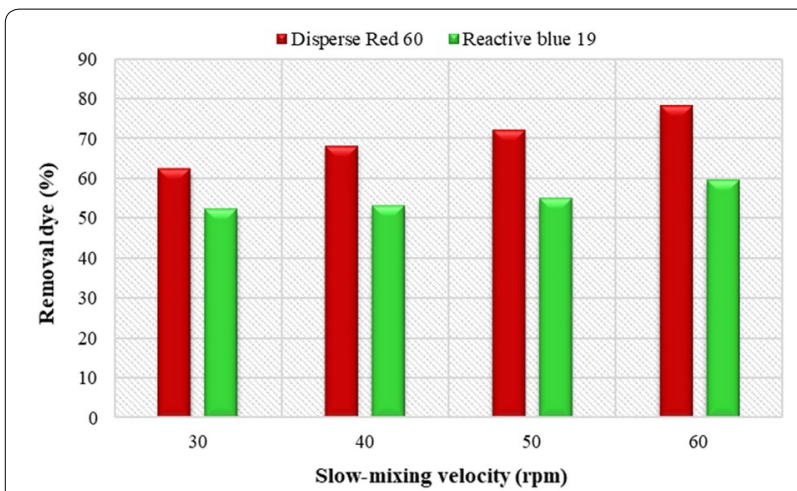

Fig. 5 Effect of slow-mixing speed on removal efficiency of Disperse red 60 and Reactive blue 19 dyes. (Initial pH=11, Alcea rosea concentration $=200 \mathrm{mg} / \mathrm{L}$ and initial dye concentration $=40 \mathrm{mg} / \mathrm{L}$ for Disperse experiments; initial $\mathrm{pH}=11$, concentration $=250 \mathrm{mg} / \mathrm{L}$ and initial dye concentration $=20 \mathrm{mg} / \mathrm{L}$ for Reactive experiments)

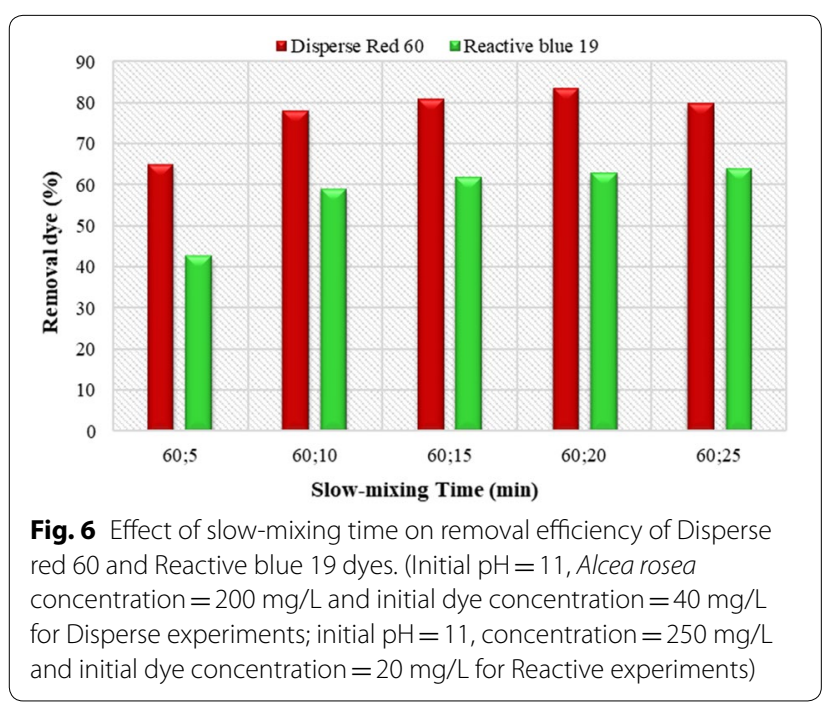

changes in the dye removal efficiency make. So, 15 min' time was chosen as the optimal time for slow mixing.

\section{Effect of settling time}

During the experiments, the settling time was $60 \mathrm{~min}$, Sampling was performed by examining the effect of different settling times on removal efficiency of the dye (Fig. 7). The results showed that obtained removal efficiency for Disperse and Reactive dyes was $60 \mathrm{~min}$ and, at a higher time; effective removal efficiency was not impressive. The results showed that removal efficiency obtained for dispersive and reactive dyes is increasing for $60 \mathrm{~min}$, and at higher rates, removal efficiency is not significant (Fig. 7). As a result, 60 min' time was chosen as optimal settling time.

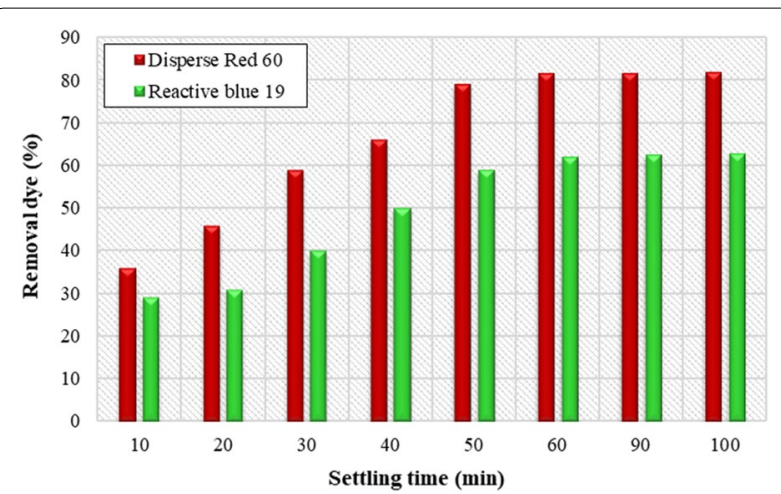

Fig. 7 Effect of settling time on removal efficiency of Disperse red 60 and Reactive blue 19 dyes. (Initial pH=11, Alcea rosea concentration $=200 \mathrm{mg} / \mathrm{L}$ and initial dye concentration $=40 \mathrm{mg} / \mathrm{L}$ for Disperse experiments; initial $\mathrm{pH}=11$, concentration $=250 \mathrm{mg} / \mathrm{L}$ and initial dye concentration $=20 \mathrm{mg} / \mathrm{L}$ for Reactive experiments; rapid-mixing speed $=180 \mathrm{rpm}$; rapid-mixing time $=3 \mathrm{~min}$; slow-mixing speed $=10 \mathrm{rpm}$; slow-mixing time $=15 \mathrm{~min}$ )

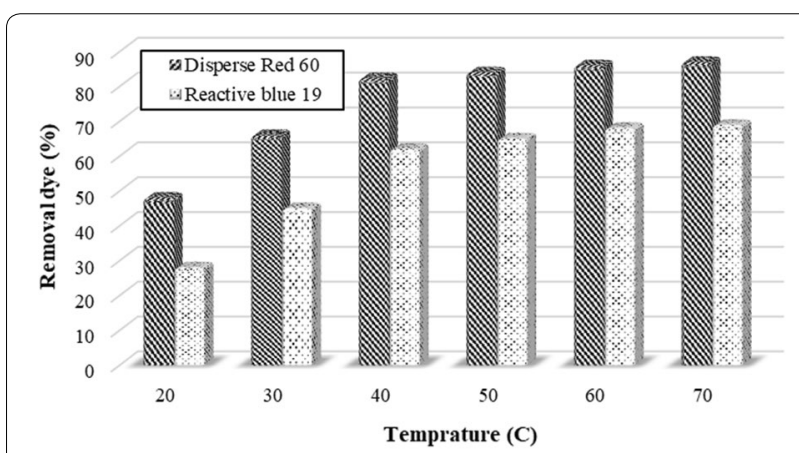

Fig. 8 The effect of Temperature on the efficiency of removal of Disperse red 60 and Reactive blue 19 dyes. (Initial pH=11, Alcea rosea concentration $=200 \mathrm{mg} / \mathrm{L}$ and initial dye concentration $=40 \mathrm{mg} / \mathrm{L}$ for Disperse experiments; initial $\mathrm{pH}=11$, concentration $=250 \mathrm{mg} / \mathrm{L}$ and initial dye concentration $=20 \mathrm{mg} / \mathrm{L}$ for Reactive experiments; rapid-mixing speed $=180 \mathrm{rpm}$; rapid-mixing time $=3 \mathrm{~min}$; slow-mixing speed $=10 \mathrm{rpm}$; slow-mixing time $=15 \mathrm{~min}$; Sedimentation time $=60 \mathrm{~min}$ )

\section{The effect of temperature}

The effect of temperature on the removal efficiency of Disperse red 60 and Reactive blue 19 dyes is shown in Fig. 8 . The nature of the curve shows that the removal efficiency of the dye has constantly increased with temperature increasing. The removal efficiency of the dye at temperatures above $60{ }^{\circ} \mathrm{C}$ did not significantly increase. So the temperature of $60{ }^{\circ} \mathrm{C}$ was chosen as the optimal temperature. The removal efficiency of Disperse red 60 and Reactive blue 19 dyes were $86 \%$ and $68 \%$, respectively. 


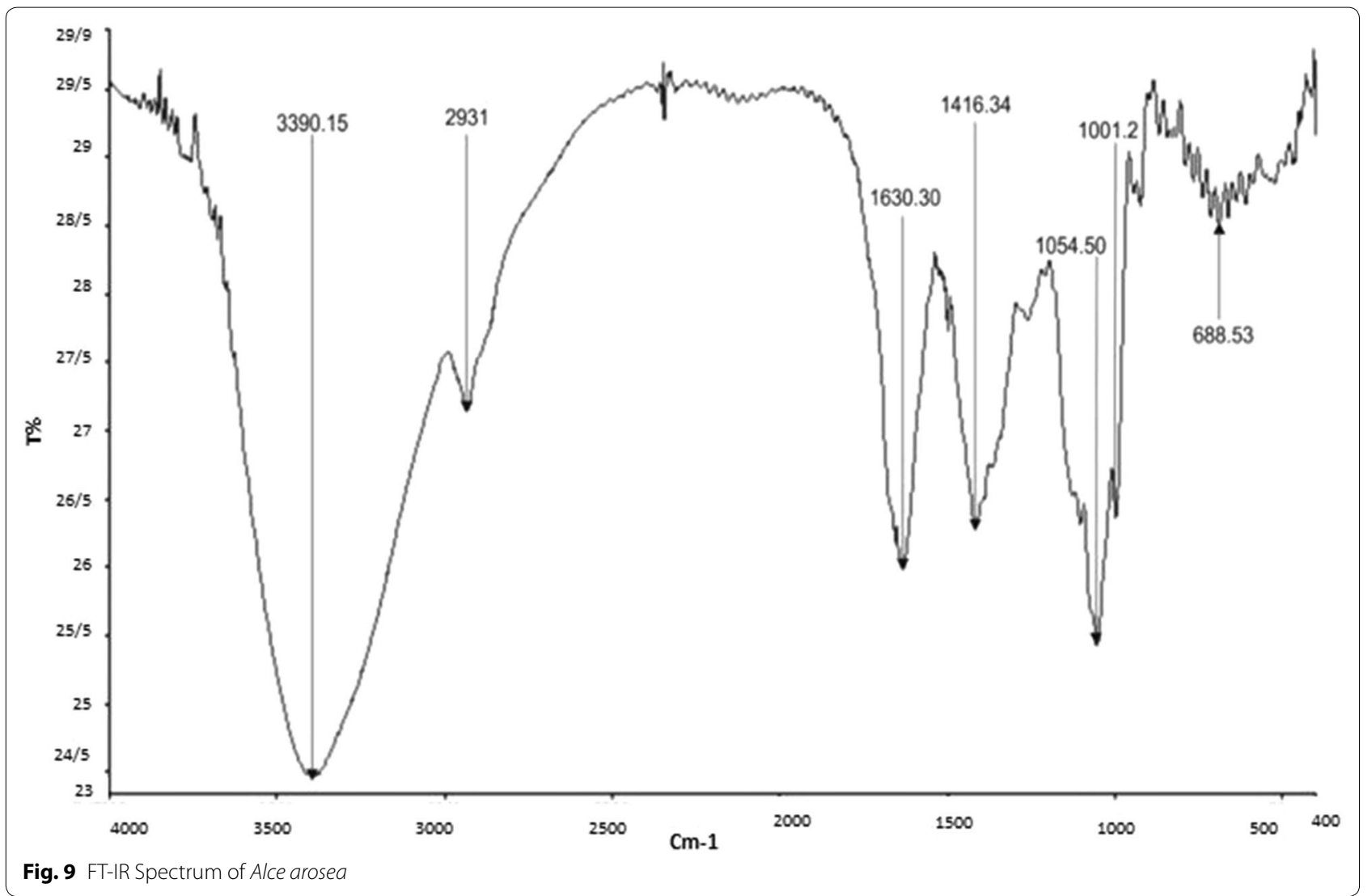

\section{FT-IR analysis}

The FT-IR spectrum of Alcea rosea is shown in Fig. 9. Alcea rosea has functional groups indifferent couriers Fig. 9. Peak $=3390 \mathrm{~cm}^{-1}$ shows the tensile vibrations of the hydroxyl functional group $(\mathrm{O}-\mathrm{H})$, while the peak $=2931 \mathrm{~cm}^{-1}$ indicates tensile vibrations of the alkaline group $(\mathrm{C}-\mathrm{H})$. Peak $=1630 \mathrm{~cm}^{-1}$ shows the tensile vibrations of the carbonyl and peak $=(\mathrm{C}=\mathrm{O})$ $1416 \mathrm{~cm}^{-1}$, shows the flexural vibrations of the hydroxyl functional group $(\mathrm{O}-\mathrm{H})$. Peak $=1054 \mathrm{~cm}^{-1}$ and $1001 \mathrm{~cm}^{-1}$ show the tensile vibrations of the functional group of alcohols $(\mathrm{C}-\mathrm{O})$ and peak $=688 \mathrm{~cm}^{-1}$ can be attributed to the flexural vibrations of the $\mathrm{C}-\mathrm{H}$ group.

\section{Discussion}

$\mathrm{pH}$ is a simple parameter but very important that most chemical reactions in the environment are controlled by changing pH value (Sher et al. 2013; Sanghi et al. 2006). The results of the experiments show that Alcea rosea root mucilage that is used as a natural coagulant in this study has no significant effect on the removal of Disperse and Reactive dyes in acidic and neutral pH. But in alkaline conditions, the removal efficiency of dye increases.
According to Alizadeh et al. the cause of the increased removal efficiency of a Reactive dye under alkaline conditions is probably due to the reaction with hydroxyl ions that forms hydroxyl fluoride (Alizadeh et al. 2014). What was observed during the experiments was the creation of fine and light flocks in acidic $\mathrm{pH}$ for both dyes, especially reactive dye, which had a low settling potential. The results of Gohary showed that removal efficiency of Disperse was higher in alkaline conditions than acidic conditions (El-Gohary and Tawfik 2009). Therefore, it is consistent with the results of this study.

The accumulation of particles in the solution can occur through four coagulation mechanisms: (1) double layer compression; (2) sweep flocculation; (3) adsorption and charge neutralization (4) adsorption and interparticle bridging (Shamsnejati et al. 2015). Natural polymer coagulants are generally related to mechanisms (3) and (4) because their long-chain structure can significantly increase the number of un-polarized sites. The presence of a large number of functional groups provides large absorption sites which leading to bridging between particles (Shamsnejati et al. 2015; Freitas et al. 2015). The mechanism of adsorption and charge neutralization refers to the absorption of two particles with opposite charges, while adsorption and interparticle bridging 
occur when a polymeric coagulant provides a polymer chain that absorbs the particles (Freitas et al. 2015). Alcea mucilage extract as an anionic polysaccharide has a similar mixture of Okra mucilage. It has a galacturonic acid. It is very important that galacturonic acid be predominantly in the polymeric form to provide a chain to absorb particles (Freitas et al. 2015). As a result, the coagulation mechanism of Alcea rosea root mucilage is a kind of adsorption and interparticle bridging.

Coagulant concentration is one of the effective factors in the variety of hydrolysis products and coagulation mechanism. Figure 4 shows that removal efficiency of the dye increases with the increasing of coagulant concentration.

However, in concentrations more than optimal value, removal efficiency reduced. The reduction in efficiency can be due to the fact that by adding a coagulant, zeta potential is formed (the potential increases with increasing coagulant concentration and as the potential become closer to zero, removal efficiency will be greater). By adding an optimal amount of coagulant, the Zeta potential becomes zero, but by adding the amount of coagulant, the Zeta potential increases and as a result, it will reduce the removal efficiency (Kim et al. 2004). The results of the study by Subramanian et al. showed that by increasing the concentration of natural coagulant, the removal efficiency of pollutants increased and it continued to a concentration of $1 \mathrm{mg} / \mathrm{L}$ and decreased in concentrations above the optimal concentration of removal efficiency (Subramonian et al. 2014) which confirms the result of the present study.

The results of Fig. 4 show that with increasing the initial dye concentration, the removal efficiency of dye increases. But after optimal dye concentration, removal efficiency for Dispersed and Reactive dyes reduces, which can be due to the reduction in the coagulant concentration in the dye solution, because there is no coagulant with increasing dye concentration that can absorb the dye particles. The study by Merzouk et al. showed that by increasing the initial concentration of Disperse red dye(more than $100 \mathrm{mg} / \mathrm{L}$ ) the removal efficiency reduced (Merzouk et al. 2012). Hence, it is consistent with the results of this study.

Slow mixing step in the coagulation process is essential for the growth and enhancement of clot (Subramonian et al. 2014). In comparison with the coagulant concentration and $\mathrm{pH}$ which are independent parameters, the speed and time of mixing depend on parameters such as angular speed $(\omega=2 \pi / T)$ which follows the function of time. "Change of factor at a time" is not used to optimize concentration and $\mathrm{pH}$, but it optimizes the speed and time of mixing. Therefore, the interaction between speed and time should be logical and carried out simultaneously
(Ghafari et al. 2010). Zhang et al. investigate the effect of slow mixing on the coagulation process by using polyaluminum chloride and report that slow mixing time is necessary to achieve optimal coagulation performance (Zhang et al. 2013). The results of the change in speed and time of mixing show that with increasing speed and time of mixing, the efficiency of dye removal increase, in this study, the settling time was measured as a parameter which affect the overall costs and coagulation process efficiency in the purification process (Subramonian et al. 2014). Although, with time increasing, the removal efficiency of Disperse and Reactive dye was increased, but the maximum settling time for both dyes was during the first $60 \mathrm{~min}$. Nevertheless, further increasing of in settling time didn't have an effect on removal efficiency, so that at $60 \mathrm{~min}$, the removal efficiency was 81.5 and $62 \%$ for Disperse and Reactive dyes, respectively. In general, the results of this study showed that Disperse dye removal efficiency was higher than Reactive dye removal that according to Kim and Park, dispersed dye materials due to their low solubility and less ratio of solved chemical oxygen demand (SCOD) to total chemical oxygen demand (TCOD) are easily removed by chemical coagulation compared to reactive dyes (Joo et al. 2007).

The results of similar studies show that coagulation efficiency is directly related to the temperature. The study of Xiao et al. showed that the efficiency of the coagulation process is reduced at low temperatures (Xiao et al. 2009).

\section{Acknowledgements \\ This study sponsored by Deputy of research and technology of Shahid Sad- oughi University of Medical Sciences, Yazd. So this articles authors appreciate the laboratory Expert and the chairman of public health collage and also the department of Environmental Health Engineering.}

\section{Authors' contributions}

Experiments were conducted by TZ. The idea was from PT and data analyses, writing and manuscript preparation were done by the remained authors. All authors read and approved the final manuscript.

\section{Funding}

Shahid Sadoughi University of Medical Sciences.

\section{Availability of data and materials}

The data of this research are inserted in the present article; other data is available if needed.

\section{Ethics approval and consent to participate}

Shahid Sadoughi University of Medical Sciences and Health Services, Yazd, Iran.

\section{Consent for publication}

Not applicable.

\section{Competing interests}

The authors declare that they have no competing interests.

\section{Author details}

${ }^{1}$ Department of Environmental Health Engineering, Shahid Sadoughi University of Medical Science, Yazd, Iran. ${ }^{2}$ Department of Environmental 
Health Engineering, Shahid Sadoughi University of Medical Science, Abarkouh Paramedical School, Yazd, Iran.

Received: 30 March 2019 Accepted: 13 July 2019

Published online: 22 July 2019

\section{References}

Ahmadi R, Khoshsokhan M, Tabatabifar Z (2014) Comparison of the effect Althea officinalis Alfalfa root extract hydroalcoholic glibenclamide on blood glucose in streptozotocin-induced rats. J Qom Univ Med Sci 8(5):68-73

Alizadeh M, Bazrafshan A, Mahvi AH, Kordmostafapour F, Ghahramani A (2014) Evaluation of the efficiency of Pistacia atlantica extract as a natural coagulant, remove reactive red 198 fromaqueoussolutions. Sci J Kurdistan Univ Med Sci 19:124-134

Al-Momani F, Touraud E, Degorce- Dumas J, Roussy J, Thomas O (2002) Biodegradability enhancement of textile dyes and textile wastewater by VUV photolysis. J photochem Photobiol 153:191-197

Cengiz STF, Aksu S, Cengiz S, Tanrikulu F, Aksu S (2012) An alternative source of adsorbent for the removal of dyes from textile waters: Posidonia oceanica. Chem Eng J 32(40):189-190

Chen W, Fan R, Wang P, Dong Y, Yang Y (2018) Multifunctional lanthanidebased metal-organic frameworks with poly heterotopic ligand: ytterbium (III)-doped for luminescence enhancement and selective dye adsorption properties. Chem Asian J 13(16):2126-2134

El-Gohary F, Tawfik A (2009) Decolorization and COD reduction of disperse and reactive dyes wastewater using chemical-coagulation followed by sequential batch reactor (SBR) process. Desalination 3:1159-1164

El-sayed GM, Kamel M, Morsy N, Taher F (2012) Encapsulation of nano Disperse red 60 via modified miniemulsion polymerization. I. Preparation and characterization. J Appl Polym Sci 125(2):1318-1329

Freitas T, Oliveira V, De Souza M, Geraldino H, Almeida V, Fávaro S, Garcia JC (2015) Optimization of coagulation-flocculation process for treatment of industrial textile wastewater using okra (A. esculentus) mucilage as natural coagulant. Ind Crops Prod 76:538-544

Ghafari S, Aziz HA, Bashir MJ (2010) The use of poly-aluminum chloride and alum for the treatment of partially stabilized leachate: a comparative study. Desalination 257(1):110-116

Guimarães JR, Maniero MG, de Araújo RN (2012) A comparative study on the degradation of RB-19 dye in an aqueous medium by advanced oxidation processes. J Environ Manag 110:33-39

Gupta VK, Jain R, Mittal A, Saleh TA, Nayak A, Agarwal S, Sikarwar S (2012) Photo-catalytic degradation of toxic dye amaranth on TiO2/UV in aqueous suspensions. Mater Sci Eng C 32(1):12-17

Haque MM, Smith WT, Wong DK (2015) Conducting polypyrrole films as a potential tool for electrochemical treatment of azo dyes in textile wastewaters. J Hazard Mater 283:164-170

Joo DJ, Shin WS, Choi J-H, Choi SJ, Kim M-C, Han MH, Ha TW, Kim YH (2007) Dedyeization of reactive dyes using inorganic coagulants and synthetic polymer. Dyes Pigm 73(1):59-64

Kasprzyk M, Gajewska M (2018) Phosphorus removal by application of natural and semi-natural materials for possible recovery according to assumptions of circular economy and closed circuit of P. Sci Total Environ 650:249-256

Kim T-H, Park C, Yang J, Kim S (2004) Comparison of disperse and reactive dye removals by chemical coagulation and Fenton oxidation. J Hazard Mater 112(1-2):95-103

Maleki A, Mahvi AH, Rezaee R, Davari B (2013) Removal of Reactive blue 19 using natural and modified zeolites. Iran J Health Environ 5(4):519-530

Maurya S, Daverey A (2018) Evaluation of plant-based natural coagulants for municipal wastewater treatment. 3 Biotech. 8(1):77

Merzouk B, Gourich B, Madani K, Vial C, Sekki A (2012) Removal of a Disperse red dye from synthetic wastewater by chemical coagulation and continuous electrocoagulation. A comparative study. Desalination 272(1-3):246-253

Moussavi G, Mahmoudi M (2009) Removal of azo and anthraquinone reactive dyes from industrial wastewaters using $\mathrm{MgO}$ nanoparticles. J Hazard Mater 168(2-3):806-812
Patel H, Vashi R (2012) Removal of congo Red dye from its aqueous solution using natural coagulants. J Saudi Chem Soc 16(2):131-136

Phalakornkule C, Polgumhang S, Tongdaung W, Karakat B (2010) Nuyut T electrocoagulation of blue reactive, red disperse and mixed dyes, and application in treating textile effluent. J Environ Manag 91(4):918-926

Raman CD, Kanmani S (2016) Textile dye degradation using nano zero valent iron: a review. J Environ Manag 177:341-355

Sanghi R, Bhattacharya B, Dixit A, Singh V (2006) Ipomoea dasysperma seed gum: an effective natural coagulant for the decolorization of textile dye solutions. J Environ Manag 81(1):36-41

Santhi T, Manonmani S, Vasantha VS, Chang YT (2016) A new alternative adsorbent for the removal of cationic dyes from aqueous solution. Arabian J Chem 9(1):466-474

Shah SA, Akhtar N, Akram M, Shah PA, Saeed T, Ahmed K et al (2011) Pharmacological activity of Althaea officinalis L. J Med Plants Res 5(24):5662-5666

Shamsnejati S, Chaibakhsh N, Pendashteh AR, Hayeripour S (2015) Mucilaginous seed of Ocimum basilicum as a natural coagulant for textile wastewater treatment. Ind Crops Prod 69:40-47

Sher F, Malik A, Liu H (2013) Industrial polymer effluent treatment by chemical coagulation and flocculation. J Environ Chem Eng 1(4):684-689

Siddique M, Farooq R, Khan ZM, Khan Z, Shaukat S (2011) Enhanced decomposition of reactive blue 19 dye in ultrasound assisted electrochemical reactor. Ultrason Sonochem 18(1):190-196

Subramonian W, Wu TY, Chai S-P (2014) A comprehensive study on coagulant performance and floc characterization of natural Cassia obtusifolia seed gum in treatment of raw pulp and paper mill effluent. Ind Crops Prod 61:317-324

Tie J, Jiang M, Li H, Zhang S, Zhang X (2015) A comparison between Moringa oleifera seed presscake extract and polyaluminum chloride in the removal of direct black 19 from synthetic wastewater. Ind Crops Prod 74(15):530-534

Veeramalini J, Sravanakumar K, Joshua Amarnath D (2012) Removal of reactive yellow dye from aqueous solutions by using natural coagulant (Moringa oleifera). Int J Sci Environ Technol 2(1):56-62

Verma AK, Dash RR (2012) Bhunia P A review on chemical coagulation/flocculation technologies for removal of colour from textile wastewaters. J Environ Manag 93(1):154-168

Vilaseca M, Lopez-Grimau V, Gutierrez-Bouzan C (2014) Valorization of waste obtained from oil extraction in Moringa Oleifera seeds: coagulation of reactive dyes in textile effluents. Materials 7(9):6569-6584

Wang H, Li Q, He N, Wang Y, Sun D, Shao W et al (2009) Removal of anthraquinone reactive dye from wastewater by batch hydrolytic-aerobic recycling process. Sep Purif Technol 67(2):180-186

Xiao M, Li L, Zhong L-F, Chen G-Q, Hang Z, Su X-Y (2009) Study on treatment of printing and dyeing wastewater by activated carbon adsorption. Liaoning Chem Ind 38(4):537-539

Yagub MT, Sen TK, Afroze S (2014) Ang HM dye and its removal from aqueous solution by adsorption: a review. Adv Colloid Interface Sci 209:172-184

Yu JX, Li B-H, Sun X-M, Jun Y, Chi R-A (2009) Adsorption of methylene blue and rhodamine $B$ on baker's yeast and photocatalytic regeneration of the biosorbent. Biochem Eng J 45(2):145-151

Zarei Mahmudabadi T, Ebrahimi AA, Eslami H, Mokhtari M, Salmani MH, Ghaneian MT, Mohamadzadeh M, Pakdaman M (2018) Optimization and economic evaluation of modified coagulation-flocculation process for enhanced treatment of ceramic-tile industry wastewater. AMB Express 8(1):172-179

Zarei Mahmoudabadi T, Abbasi F, Jalili M, Talebi P (2019) Effectiveness of Plantago major extract as a natural coagulant in removal of Reactive Blue 19 dye from wastewater. Int J Environ Sci Techno 16:1-8

Zhang Z, Dan L, Dandan H, Duo L, Xiaojing R, Cheng Y et al (2013) Effects of slow-mixing on the coagulation performance of polyaluminium chloride (PACI). Chin J Chem Eng 21(3):318-323

Zodi S, Merzouk B, Potier O, Lapicque F (2013) Leclerc J-P Direct red 81 dye removal by a continuous flow electrocoagulation/flotation reactor. Sep Purif Technol 108:215-222

\section{Publisher's Note}

Springer Nature remains neutral with regard to jurisdictional claims in published maps and institutional affiliations. 